\title{
A Reavaliação do Registro de Agrotóxicos e o Direito à SAÚde
}

\author{
PESTICIDE'S REGISTRATION \\ REAPPRAISAL AND THE RIGHT TO HEALTH
}

Maria Célia Delduque ${ }^{(*)}$

Silvia Badim Marques ${ }^{(* *)}$

Letícia Rodrigues da Silva ${ }^{(* * *)}$

A partir de 2000, o Brasil, por intermédio da Agência Nacional de Vigilância Sanitária, deu início às reavaliações toxicológicas de alguns produtos

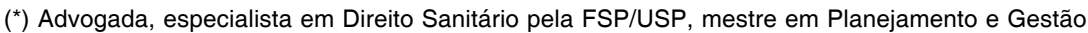
Ambiental pela UCB, doutoranda em Saúde Pública pela FSP/USP, Pesquisadora da Fundação Oswaldo Cruz. E-mail <delduque@ delduque.com.br>

${ }^{(* *}$ Bacharel em Direito, mestre em Saúde Pública pela FSP/USP, doutoranda em Saúde Pública pela FSP/USP, pesquisadora colaboradora da Fundação Oswaldo Cruz.

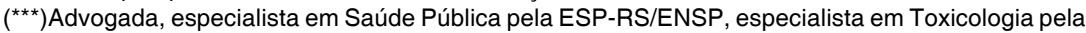
ENSP, gerente de Normatização e Avaliação da ANVISA. Recebido em 10.09.08. Revisado em 26.09.08. Revisado novamente em 01.10.08. Aprovado em 10.02.09. 
agrotóxicos que já estavam registrados para comercialização em território nacional, por apresentarem alterações de risco à saúde humana. Ou seja, com base em pesquisas nacionais e internacionais, e também em condenações judiciais das empresas fabricantes desses produtos por agravos à saúde das pessoas, no exterior, a autoridade sanitária federal, considerou fundamental reavaliá-los, para que a população brasileira, consumidora de culturas tratadas com estes agrotóxicos, bem como trabalhadores rurais que os manejam, não estivessem expostos a riscos inaceitáveis à vida e à saúde.

Os produtos químicos mais tóxicos utilizados para fins agronômicos e aqueles com possibilidade de causar efeitos crônicos, tais como carcinogenicidade, desregulação endócrina, imunotoxicidade, efeitos reprodutivos e neurotoxicidade têm merecido uma atenção especial dos governos. Há histórias de banimentos e restrições severas destes produtos em muitos países, a exemplo do Japão, Estados Unidos, Canadá e Comunidade Europeia. Mas muitos desses produtos mantêm sua venda regular no Brasil.

A decisão de reavaliar toxicologicamente alguns agrotóxicos, seus componentes e afins, teve sua base legal instituída pela Lei n. 7.802/89, que dispõe sobre a competência das autoridades brasileiras a tomarem medidas necessárias mediante alerta de organizações internacionais quanto ao risco no uso de agrotóxicos. Igualmente, o Decreto n. 4.074/02 fixa a competência do Ministério da Saúde, entre outros, para reavaliar o registro de agrotóxicos e de seus componentes, quando surgirem indícios da ocorrência de riscos para a saúde humana.

A Instrução Normativa Conjunta Anvisa, Ibama e MAPA n. 02, de 27 de setembro de 2006, estabelece em seu art. $1^{\circ}$ que as reavaliações poderão ser efetuadas por iniciativa de qualquer um dos órgãos federais envolvidos no processo de avaliação.

A referida norma também impõe à atividade reavaliadora a condição de constituir-se uma comissão a convite do órgão responsável pelo aspecto a ser reavaliado, composta pelas autoridades federais responsáveis pelos setores da vigilância sanitária, meio ambiente e agricultura e podendo ainda, ser convidados representantes do setor privado de agrotóxicos e da comunidade científica, além da publicação obrigatória na imprensa oficial federal, sobre o nome químico e comum do ingrediente ativo, marcas comerciais registradas que utilizam o ingrediente ativo, números de seus registros e respectivos titulares e o motivo da reavaliação.

No que se refere ao Acefato, a reavaliação do registro, por parte da Anvisa, teve como justificativa a necessidade da revisão da Ingesta Diária Aceitável (IDA) do produto no Brasil, que se encontra com valor muito superior do que a ingestão máxima aceita por outros países, como por exemplo, os Estados Unidos da América.

O Acefato é um agrotóxico do grupo químico dos organofosforados. Os agrotóxicos desse grupo químico vêm passando por restrições e programas 
de substituição por produtos menos tóxicos, em países e blocos econômicos como Estados Unidos e Comunidade Europeia, porque causam alterações na acetilcolinesterase e porque podem estar associados a efeitos neurotóxicos em trabalhadores e consumidores de culturas tratadas ${ }^{(1)}$. Há suspeita que esses efeitos podem alterar o sistema cognitivo, cuja gravidade, para crianças que sejam expostas a essas substâncias, é ainda desconhecida. No meio ambiente o produto é tóxico para as abelhas e prejudicial para aves e invertebrados aquáticos ${ }^{(2)}$.

A Agência de Proteção Ambiental dos Estados Unidos (Environmental Protection Agency - EPA) classifica o acefato como Possível Carcinógeno para Humanos, classe $\mathbf{C}^{(3)}$. São enquadradas nessa classe as substâncias para as quais há evidências de carcinogenicidade obtidas em estudos experimentais com animais, mas que não foram adequadamente avaliadas em seres humanos. A ANVISA, portanto, motivada por tais evidências, e pelo respaldo legal de sua função, deu inicio ao processo de reavaliação desta substância no Brasil.

Neste contexto, merece destaque a importância do princípio da precaução para o exercício do poder de polícia das autoridades sanitárias, principalmente no que tange ao registro de produtos agrotóxicos. Constata-se que este princípio é de suma importância no momento do registro ou da reavaliação de produtos agrotóxicos, o que diminuiria o potencial risco do consumo dessa substância pela população brasileira. Em casos de incerteza científica, inclusive, o princípio da precaução pode justificar a restrição comercial destes produtos.

O princípio da precaução foi utilizado pela primeira vez no direito ambiental alemão, na década de $1970^{(4)}$. No mesmo período, os legisladores norte-americanos introduziram esse princípio nas suas leis ambientais, mas foi na Declaração do Rio de Janeiro, sobre Meio Ambiente e Desenvolvimento, da Conferência das Nações Unidas, realizada em 1992, que a precaução foi consagrada expressamente, estando inscrita no princípio n. 15:

De modo a proteger o meio ambiente, o princípio da precaução deve ser amplamente observado pelos Estados, de acordo com suas capacidades. Quando houver ameaça de danos sérios ou irreversíveis, a ausência de absoluta certeza científica não deve ser utilizada como razão para postergar medidas eficazes e economicamente viáveis para prevenir a degradação ambiental. (grifo nosso)

(1) <http://cheminova.com.br/pdf/fispg/FISPQ20Aquila.pdfco>. Acesso em 22 dez. 2009.

(2) Id. Ibid.

(3) REIGAT, J. Routt; ROBERTS, James, R. Reconocimiento y manejo de los envenenamientos por pesticides. 1999. Disponível em <http://www.epa.gov/pesticides/safety/healthcare.

(4) DALLARI, Sueli Gandolfi; VENTURA, Daisy de Freitas Lima. O princípio da precaução: dever do Estado ou protecionismo disfarçado? São Paulo em Perspectiva, São Paulo, v. 2, n. 16, p. 5, 2002. 
Merece nota a relação que há entre a gravidade da ameaça de dano ao meio ambiente e à saúde e o grau de incerteza científica presente em cada caso concreto, e a aplicabilidade do princípio da precaução. "Naquelas circunstâncias em que o dano sob apreciação é considerado muito grave, pode ser observado um relaxamento nas exigências de indicativos objetivos da plausividade de sua concretização. Já nas hipóteses em que a ameaça não é considerada tão grave, exige-se um grau maior de certeza científica para se tornar obrigatória a adoção de medidas de precaução"(5).

Em relação ao Acefato e outros agrotóxicos, uma das dificuldades encontra-se na geração de conhecimentos científicos sobre seus riscos, uma vez que existem poucos laboratórios de toxicologia que atuam nesta seara, escassos estudos epidemiológicos que abordam intoxicações por agrotóxicos, e fragilidade nas notificações dos casos de intoxicação, na medida em que a população mais exposta são os trabalhadores rurais, não raras vezes residentes distantes dos centros urbanos e do acesso aos serviços de saúde.

Há de se destacar também que é possível depreender da Constituição Federal de 1988, muito embora não tenha ela declarado expressamente o Princípio da Precaução, que quis o legislador constituinte adotar uma postura de segurança diante da dúvida e da incerteza em relação à saúde e ao meio ambiente, tanto que no art. 196 declara ser dever do Estado garantir a redução do risco de doença e de outros agravos à saúde e no art. 225 , inciso V impõe o dever de controle da produção, da comercialização e do emprego de técnicas, métodos e substâncias que comportem risco para a vida, a qualidade de vida e o meio ambiente. Portanto, a Constituição Federal de 1988 tutela o princípio da precaução.

E é exatamente porque em relação ao Acefato não se pode comprovar todas as suspeitas de danos provocados no ambiente e na saúde humana, que a certeza científica deve ser apurada, criteriosamente, a fim de se aplicar o princípio da precaução, negando-se a manutenção do registro, no caso de reavaliação, ou ainda, constatando-se que este produto pode continuar a ser comercializado no Brasil, sem que este fato exponha a saúde humana e do meio ambiente a risco.

A reavaliação deste produto pela ANVISA foi motivada por resultados de estudos epidemiológicos e experimentos científicos com animais que reportaram que o produto causa neurotoxicidade, demonstra suspeita de carcinogenicidade para seres humanos e de toxicidade reprodutiva, empreendidos por renomadas instituições de pesquisa nacionais e estrangeiras ${ }^{(6)}$.

(5) WOLD, Chris. Introdução ao estudo dos princípios de direito internacional do meio ambiente. In: Princípios de direito ambiental na dimensão internacional e comparada. Belo Horizonte: Del Rey, 2003.

(6) BEDOR, Cheila Nataly Galindo. Estudo do potencial carcinogênico dos agrotóxicos empregados na fruticultura e sua implicação para a vigilância da saúde. Tese (Doutorado em Saúde Pública) Centro de Pesquisas Aggeu Magalhães, Fundação Oswaldo Cruz, em 26/4/2008. Mimeo. 
Tal ato administrativo foi motivado, ainda, pela necessidade de revisar a Ingestão Diária Aceitável do produto, bem como as restrições internacionais estabelecidas para agrotóxicos perigosos à saúde humana por estados nacionais, blocos econômicos e convenções internacionais de saúde e meio ambiente ratificadas pelo Brasil.

E para proceder a reavaliação dos registros dos produtos à base de Acefato, a agência editou a RDC 10/2008, de 22 de fevereiro de 2008, que determinou a constituição de uma Comissão reavaliadora de alguns produtos agrotóxicos, dentre eles o ingrediente ativo Acefato. A Comissão Técnica assim constituída foi composta por dois representantes das seguintes entidades: Instituto Brasileiro do Meio Ambiente e Recursos Renováveis - Ibama, Ministério da Agricultura e do Abastecimento - MAPA, Sindicato Nacional da Indústria de Produtos para Defesa Agropecuária - SINDAG e representantes da Agência Nacional de Vigilância Sanitária - Anvisa, que convidou representantes da comunidade científica. Evidencia-se, portanto, que a Agência envolveu, em sua tomada de decisão, outros atores envolvidos na temática.

Na parte dispositiva da sentença em estudo, há a afirmação de que "a composição do Acefato é matéria que envolve grande polêmica científica e que exige profundas discussões para se chegar a um consenso sobre o seu índice de IDA - Ingesta Diária Aceitável'. Ora, tal afirmativa enseja a aplicação do princípio da precaução, em vista, exatamente, da grande polêmica científica sobre o Acefato. Polêmica esta que motiva, justificadamente, o ato de reavaliação deste produto agrotóxico por parte da autoridade sanitária.

A referida sentença ainda colaciona decisão tomada em sede de Agravo de Instrumento em que são destacada questões procedimentais. O fato é que, a decisão foca tão somente o aspecto formal dos procedimentos, passando ao largo da discussão de direito objetivo implícito na ação. Tal acontece porque o próprio direito processual alberga uma infinidade de recursos, que podem ser transformados em recursos meramente protelatórios de uma decisão. Pode-se dizer, inclusive, que há uma preocupação grande por parte dos juízes com as minúcias processuais, formais, e no caso em tela o direito material, escondido por trás das formalidades, ficou em compasso de espera.

Mesmo em relação aos aspectos formais, é importante salientar que a Agência não agiu de forma unilateral. Além da ANVISA ter discutido a questão em Comissão composta, inclusive, por representantes das empresas interessadas na comercialização de produtos agrotóxicos no Brasil, o ato de reavaliação do referido produto é legítimo, posto que se enquadra dentre as competências da autoridade sanitária em questão.

O art. $2^{\circ}$ da Lei n. 9.782/99, em seus incisos III e VII, respectivamente, atesta expressamente que compete à ANVISA "normatizar, controlar e fisca- 
lizar produtos, substâncias e serviços de interesse para a saúde" e "atuar em circunstâncias especiais de risco à saúde". O art. $7^{\circ}$ da referida Lei estabelece, ainda, que a Agência deve "fomentar e realizar estudos e pesquisas no âmbito de suas atribuições" (inciso II), "estabelecer normas e padrões sobre limites de contaminantes, resíduos tóxicos, desinfetantes, metais pesados e outros que envolvam risco à saúde" (inciso IV); "proibir a fabricação, a importação, o armazenamento, a distribuição e a comercialização de produtos e insumos, em caso de violação da legislação pertinente ou de risco iminente à saúde" (inciso XV).

O Art. $8^{\circ}$, parágrafo $1^{\circ}$ da citada lei expressa ainda que:

Consideram-se bens e produtos submetidos ao controle e fiscalização sanitária pela Agência: II - alimentos, inclusive bebidas, águas envasadas, seus insumos, suas embalagens, aditivos alimentares, limites de contaminantes orgânicos, resíduos de agrotóxicos e de medicamentos veterinários"; "XI quaisquer produtos que envolvam a possibilidade de risco à saúde..." (grifo nosso)

Ora, proceder à reavaliação de um produto agrotóxico, num contexto de potencial risco à saúde da população, mediante a realização de estudos e pesquisas tendentes a verificar os riscos e o índice de ingestão tolerável desta substância pela população, é um ato administrativo que se enquadra perfeitamente dentre as competências legais da Agência. Não há que se falar em unilateralidade, visto que a autoridade sanitária em questão estava perfeitamente embasada na legislação para proceder a este ato, e convocou os demais interessados para discuti-lo. E não há que se falar, tampouco, em ato abusivo, visto que o ato foi motivado e expedido de acordo com as determinações legais, no sentido de proteger a saúde da população. O que evidencia que não houve lesão a qualquer direito líquido e certo do impetrante.

Ressalta-se ainda que o processo de reavaliação não implica necessariamente o cancelamento do registro do agrotóxico em questão. É um procedimento de investigação, que pode ou não levar a proibição ou restrição da comercialização do produto em território nacional. O princípio da precaução mostra-se perfeitamente aplicável a este caso concreto pelo Poder Judiciário, no sentido de proteger à saúde da população em vista da incerteza científica, e permitir a continuidade da reavaliação do produto em questão pela autoridade sanitária. Mas, ao revés, a sentença acatou o pedido da empresa fabricante do Acefato no Brasil, e determinou a suspensão do processo de reavaliação.

Este caso ilustra o dilema atual dos conflitos jurídicos que envolvem este direito novo, o direito sanitário, e que acabam batendo às portas do Judiciário. Ao chegar ao Judiciário, esbarram em juízes que não contam com uma tradição legal e doutrinária (há pouca produção intelectual sobre o tema) e, muito menos, com precedentes de decisões pretorianas que repre- 
sentem um pensamento jurídico novo, fazendo com que as decisões aconteçam em um campo recente e não consensual.

O que os cidadãos esperam, ao revés, é a atuação de um juiz sensível à questão da saúde, um juiz-cidadão, aquele que vai além, que contesta o sistema, cria e inova, que se norteia pela prevalência da vida e da saúde e pela precaução, prudência e cautela, no lugar do juiz burocrata, mero aplicador da lei.

\section{REFERÊNCIAS BIBLIOGRÁFIAS}

BEDOR, Cheila Nataly Galindo. Estudo do potencial carcinogênico dos agrotóxicos empregados na fruticultura e sua implicação para a vigilância da saúde. Tese (Doutorado) em Saúde Pública) - Centro de Pesquisas Aggeu Magalhães, Fundação Oswaldo Cruz, em 26/4/2008. Mimeo.

CHEMINOVA. Disponível em: <http://cheminova.com.br/pdf/fispg/FISPQ20Aquila. pdfco>. Acesso em 22 dez. 2009.

DALLARI, Sueli Gandolfi; VENTURA, Daisy de Freitas Lima. O princípio da precaução: dever do Estado ou protecionismo disfarçado? São Paulo em Perspectiva, São Paulo, v. 2, n. 16, 2002.

REIGART, J. Routt; ROBERTS, James, R. Reconocimiento y manejo de los envenenamientos por pesticides. 5. ed. Washington: Envelonmental Protection Agency, 1999. Disponível em <http://www.epa.gov/pesticides/safety/ healthcare. Acesso em 20 dez 2009.

WOLD, Chris. Introdução ao estudo dos princípios de direito internacional do meio ambiente. In: Princípios de direito ambiental na dimensão internacional e comparada. Belo Horizonte: Del Rey, 2003. 